\title{
N-ACETYLCYSTEINE EFFECT ON GENTAMICIN INDUCED NEPHROTOXICITY IN ANIMAL MODELS
}

\author{
Laishram Elizabeth Devi' ${ }^{1}$ Usham Dhamaraj Meetei2 ${ }^{2}$ Khuraijam Sucheta Devi3, Victoria Laishram ${ }^{4}$
}

${ }_{1}^{1}$ Post Graduate Trainee, Department of Pharmacology, Regional Institute of Medical Sciences, Imphal.

${ }^{2}$ Assistant Professor, Department of Pharmacology, Regional Institute of Medical Sciences, Imphal.

${ }^{3}$ Assistant Professor, Department of Pathology, Regional Institute of Medical Sciences, Imphal.

${ }^{4}$ Post Graduate Trainee, Department of Biochemistry, Regional Institute of Medical Sciences, Imphal.

\begin{abstract}
\section{BACKGROUND}

Gentamicin exerts a unique pharmacokinetic effect on renal physiology and its use at high dose or prolonged treatment requires monitoring of kidney function test. Antioxidants has been claimed to have nephroprotective potential and hence antioxidant compound, $\mathrm{N}$-acetylcysteine (NAC) has been used in renal impairment; however, its efficacy is not very well documented. Therefore, the present study has been undertaken to evaluate the role of antioxidant (NAC) in impaired kidney function due to high dose Gentamicin in rat models. Gentamicin at the dose of $80 \mathrm{mg} / \mathrm{kg} \mathrm{b.w.} \mathrm{intramuscularly} \mathrm{was} \mathrm{given} \mathrm{in} 18$ adult healthy albino rats for 10 days and varying doses of antioxidant NAC $(20$ and $40 \mathrm{mg} / \mathrm{kg}$ ) were given orally for 3 wks. starting from day 5 of the experiment. Blood urea and creatinine levels were measured on day 5, 10 and after completion of treatment of NAC and histopathology examination conducted. Intramuscular injection of high dose of Gentamicin significantly produced biochemical signs of nephrotoxicity. Serum creatinine levels were significantly lowered in NAC treated group compared to the control group. The group treated with NAC $40 \mathrm{mg} / \mathrm{kg}$ for 3 wks. had significantly lowered renal biochemical parameters and histopathological features compared to control.
\end{abstract}

\section{KEYWORDS}

Gentamicin, N-acetylcysteine, Nephrotoxicity.

HOW TO CITE THIS ARTICLE: Devi LE, Meetei UD, Devi KS, et al. N-acetylcysteine effect on gentamicin induced nephrotoxicity in animal models. J. Evolution Med. Dent. Sci. 2016;5(42):2617-2620, DOI: 10.14260/jemds/2016/612

\section{INTRODUCTION}

Alteration in renal function is one of the most commonly encountered effect as the kidney's central role in removal of drugs and metabolites makes it susceptible to adverse drug effects.[1] Nephrotoxic injury occurs in response to a number of pharmacologic compounds with diverse structures, endogenous substances and environmental exposures. Nephrotoxic potential of aminoglycosides such as gentamicin are well documented and require monitoring of serum creatinine level. Nephrotoxicity caused by gentamicin at therapeutic doses is usually reversible and mild occurring in $5-25 \%$ of patients receiving gentamicin for longer than 3-5 days.[2] but prolonged and high dose can adversely affect the renal status. $\mathrm{N}$-acetylcysteine (NAC) has been claimed to have nephroprotective potential. It has been used in renal impairment, whereas some appear to cast doubt on its efficacy. Even though there are various reports and studies on the role of acetylcysteine in renoprotection, conflicting results continues in the studies. Therefore, the present study has been undertaken to evaluate the role of acetylcysteine in impaired kidney function in suitable experimental animal models.

\section{MATERIALS AND METHODS}

Adult albino rats of either sex weighing between 150 and 250 gm were obtained from the central animal house RIMS, Imphal.

Financial or Other, Competing Interest: None.

Submission 05-02-2016, Peer Review 05-05-2016,

Acceptance 11-05-2016, Published 26-05-2016.

Corresponding Author:

Dr. Laishram Elizabeth Devi,

Department of Pharmacology,

Regional Institute of Medical Sciences,

Imphal.

E-mail:laishram.e@gmail.com

DOI: $10.14260 /$ jemds/2016/612
The animals were housed in standard conditions of temperature, relative humidity $(55 \pm 5 \%)$, and light $(12 \mathrm{~h}$ light/dark cycles). They were fed with standard pellet diet and water ad libitum. Animals with serum urea level in the range of $10-45 \mathrm{mg} / \mathrm{dL}$ and serum creatinine level in the range of $0.5-$ $1.4 \mathrm{mg} / \mathrm{dL}$ were chosen for the study. The animals were divided into 3 subgroups of control, Test I, Test II of 6 animals each (Total 18 animals). All animals were given Inj. Gentamicin $80 \mathrm{mg} / \mathrm{kg}$ bw/day for 10 days.[3] Nephrotoxicity were said to induce significantly when serum creatinine values were $>0.5$ $\mathrm{mg} / \mathrm{dL}$ of baseline value after 5 days of drug administration. Test drug (NAC) were started from day 5 of induced nephrotoxicity and given for 3 weeks at the following doses in the respective test groups. Test I group of animals received 20 $\mathrm{mg} / \mathrm{kg}$ bw of NAC orally. And test II group of animals received $40 \mathrm{mg} / \mathrm{kg}$ bw of NAC orally. Control group were given $2 \%$ gum acacia orally. On the 26th day of the experiment, the animals were sacrificed by high ether anaesthesia and kidney were taken for histopathological examination.

Biochemical Assay: Blood urea and creatinine level were estimated by Direct Colorimetric method using Diacetyl Monoxime Reagent and Alkaline Picrate Method as described by McLauchlan DM.[4]

Pathological Scoring: The renal samples taken for histology were fixed overnight in 10\% neutral buffered formalin, processed, sectioned and stained with haematoxylin and eosin. The histological scoring was performed as a combined score of the following 5 parameters assessed and graded as per guidelines of FDA with some modification.[5] Tubular degeneration, Necrosis, Tubular dilatation, Hyaline protein casts, Interstitial leucocytic infiltration.

The above parameters are assessed and scored as mild, moderate, and severe. 
Grading (Scale of 0 to 5).

$0=$ normal histology.

$1=$ degeneration only without necrosis.

$2=<25 \%$.

$3=>25 \%$, but $<50 \%$.

$4=>50 \%$, but $<75 \%$.

$5=>75 \%$.

\section{Statistical Analysis}

The tests of significance of the results of serum urea and creatinine were calculated using one-way ANOVA test followed by Dunnet's ' $\mathrm{t}$ ' test. $\mathrm{P}$ value less than 0.05 was considered significant: $P$ value less than 0.01 , highly significant; $P$ value less than 0.001 , very highly significant.

Approval of Institutional Ethics Committee: The number of animals used and the procedures conducted were approved by the Institutional Animal Ethics Committee (IAEC) $1596 / \mathrm{GO} / \mathrm{a} / 12 / \mathrm{CPCSEA}$ according to the regulation of Committee for the Purpose of Control and Supervision of Experiments on Animals (CPCSEA). Throughout the experiments, animals were handled according to the suggested ethical guideline for the care of laboratory animals.

Animal Disposal: The animal carcasses were buried deep in the ground covered with lime and disinfectants after the experiment.[6]

\section{RESULTS}

The serum creatinine values on Day 5 for Control, Test I, Test II are $1.70 \pm 0.10,1.80 \pm 0.07,1.84 \pm 0.08$ respectively. These values are significant from their respective baseline values at $P$ value
$<0.001$. The value for Test I after 3 weeks of treatment with NAC $20 \mathrm{mg} / \mathrm{kg}$ was $1.68 \pm 0.10$, which was significant compared to Day 5 value of $1.80 \pm 0.07$ at $P$ value $<0.05$. The creatinine value for Test II after 3 weeks of treatment with NAC $40 \mathrm{mg} / \mathrm{kg}$ was $1.54 \pm 0.05$, which was significant compared to Day 5 value of $1.84 \pm 0.08$ at $P$ value $<0.001$. The creatinine values for Test I and Test II on day 26 was $1.68 \pm 0.10$ and $1.54 \pm 0.05$ respectively. These values are significant compared to the value for control on day 26 at $P$ value $<0.001$. The serum urea values on Day 5 for Control, Test I, Test II are 48.76 \pm 1.03 , $47.90 \pm 0.95,49.06 \pm 1.17$ respectively. These values are significant from their respective baseline values at $\mathrm{P}$ value $<0.001$. The serum urea values for Test I and Test II after 26th day was $47.00 \pm 1.14$ and $45.20 \pm 2.28$ respectively. These values are significant compared to the value for control group after 3 weeks at $\mathrm{P}$ value $<0.05$.

\section{Histological Examination}

The processed histological slides were examined by pathologist at Dept. of Pathology, RIMS, Imphal. The renal histological parameters of tubular degeneration, Tubular dilatation, Hyaline cast and Interstitial leucocytic infiltration were examined and scoring was done as none $(-)$, mild $(+)$, moderate $(++)$, severe $(+++)$. The histopathological parameter scores were graded to a scale from 0 to 5 according to FDA guidelines. The control group was graded a score of $>75 \%$ and Test I and Test II were graded a score of $>50 \%$, but $<75 \%$ and $>50 \%$, but $<75 \%$ respectively. Hence, the grading of control, Test I and Test II was scale as 5, 4 and 4 respectively.

\begin{tabular}{|c|c|c|c|c|}
\hline & Baseline & Day 5 & Day 10 & Day 26 \\
\hline Control & $0.78 \pm 0.08$ & $* 1.70 \pm 0.10$ & $1.94 \pm 0.05$ & $2.04 \pm 0.05$ \\
\hline Test I & $0.82 \pm 0.08$ & $* 1.80 \pm 0.07$ & $1.96 \pm 0.11$ & $\# * * 1.68 \pm 0.10$ \\
\hline Test II & $0.84 \pm 0.08$ & $* 1.84 \pm 0.08$ & $1.68 \pm 0.10$ & $\# * 1.54 \pm 0.05$ \\
\hline $\begin{array}{c}\text { One-Way ANOVA } \\
\text { Between Group F } \\
\text { P }\end{array}$ & 0.63 & 3.39 & 13.07 & 55.44 \\
\cline { 2 - 5 } & $>0.05$ & $>0.05$ & $<0.05$ & $<0.001$ \\
\hline
\end{tabular}

Values are mean $\pm \mathrm{SEM},{ }^{*} \mathrm{P}<0.001$, highly significant compared to baseline on Day 5 ; \#P<0.05, significant compared to Day 5 , ${ }^{* *} \mathrm{P}<0.05$, significant compared to control on Day 26.

\begin{tabular}{|c|c|c|c|c|}
\hline & Baseline & Day 5 & Day 10 & Day 26 \\
\hline Control & $23.18 \pm 5.53$ & $* 48.76 \pm 1.03$ & $51.8 \pm 0.72$ & $52.32 \pm 0.93$ \\
\hline Test I & $27.98 \pm 6.91$ & $* 47.90 \pm 0.95$ & $48.14 \pm 1.07$ & $* * 47.00 \pm 1.14$ \\
\hline Test II & $31.96 \pm 7.91$ & $* 49.06 \pm 1.17$ & $48.72 \pm 1.88$ & $* * 45.20 \pm 2.28$ \\
\hline \multirow{2}{*}{ One-Way ANOVA } & $\mathrm{F}=2.05$ & $\mathrm{~F}=1.613$ & $\mathrm{~F}=11.056$ & $\mathrm{~F}=27.70$ \\
\cline { 2 - 5 } & $\mathrm{P}>0.05$ & $\mathrm{P}>0.05$ & $\mathrm{P}<0.05$ & $\mathrm{P}<0.05$ \\
\hline
\end{tabular}

Values are mean $\pm \mathrm{SEM},{ }^{*} \mathrm{P}<0.001$, highly significant compared to baseline on Day 5 ; ${ }^{* *} \mathrm{P}<0.05$, significant compared to control on Day 26.

\begin{tabular}{|c|c|c|c|}
\hline Histological Parameters & Control & Test I & Test II \\
\hline Tubular degeneration & +++ & ++ & ++ \\
\hline Tubular necrosis & +++ & +++ & ++ \\
\hline Tubular dilatation & +++ & +++ & ++ \\
\hline Hyaline cast & + & + & + \\
\hline $\begin{array}{c}\text { Interstitial leukocytic } \\
\text { infiltration }\end{array}$ & +++ & +++ & +++ \\
\hline
\end{tabular}




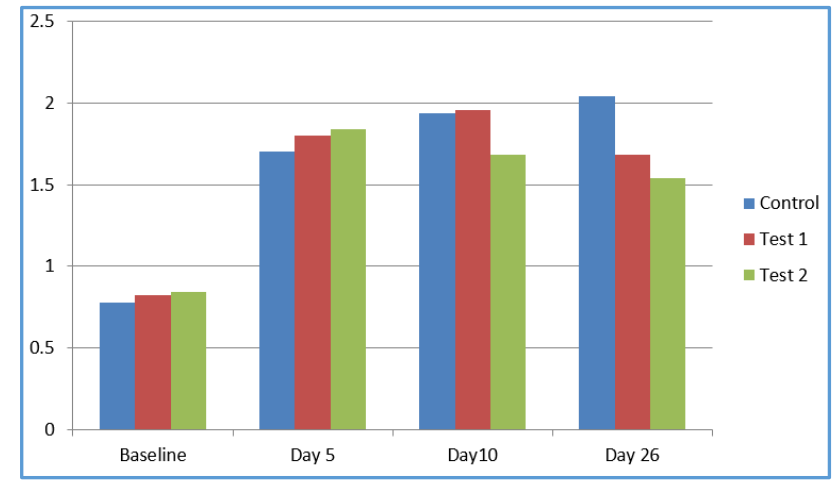

Fig. 1: Effect of NAC on Serum Creatinine Level in Gentamicin Induced Group of Animals

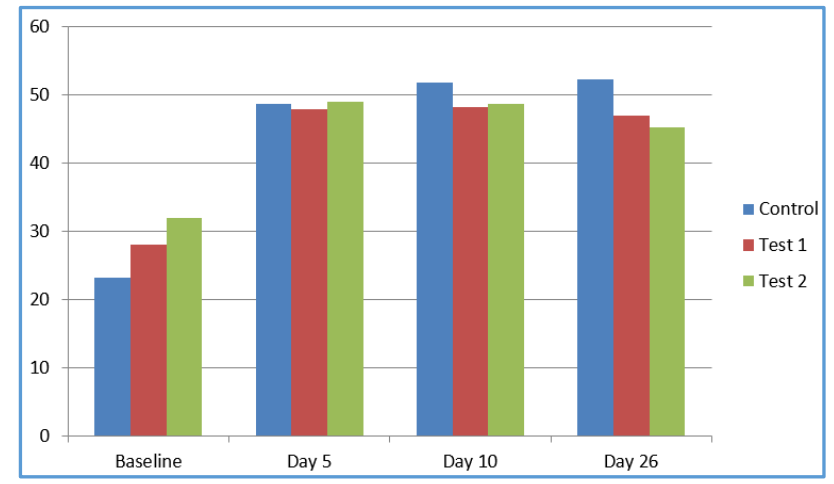

Fig. 2: Effect of NAC on Serum Urea Level in Gentamicin Induced Group of Animals

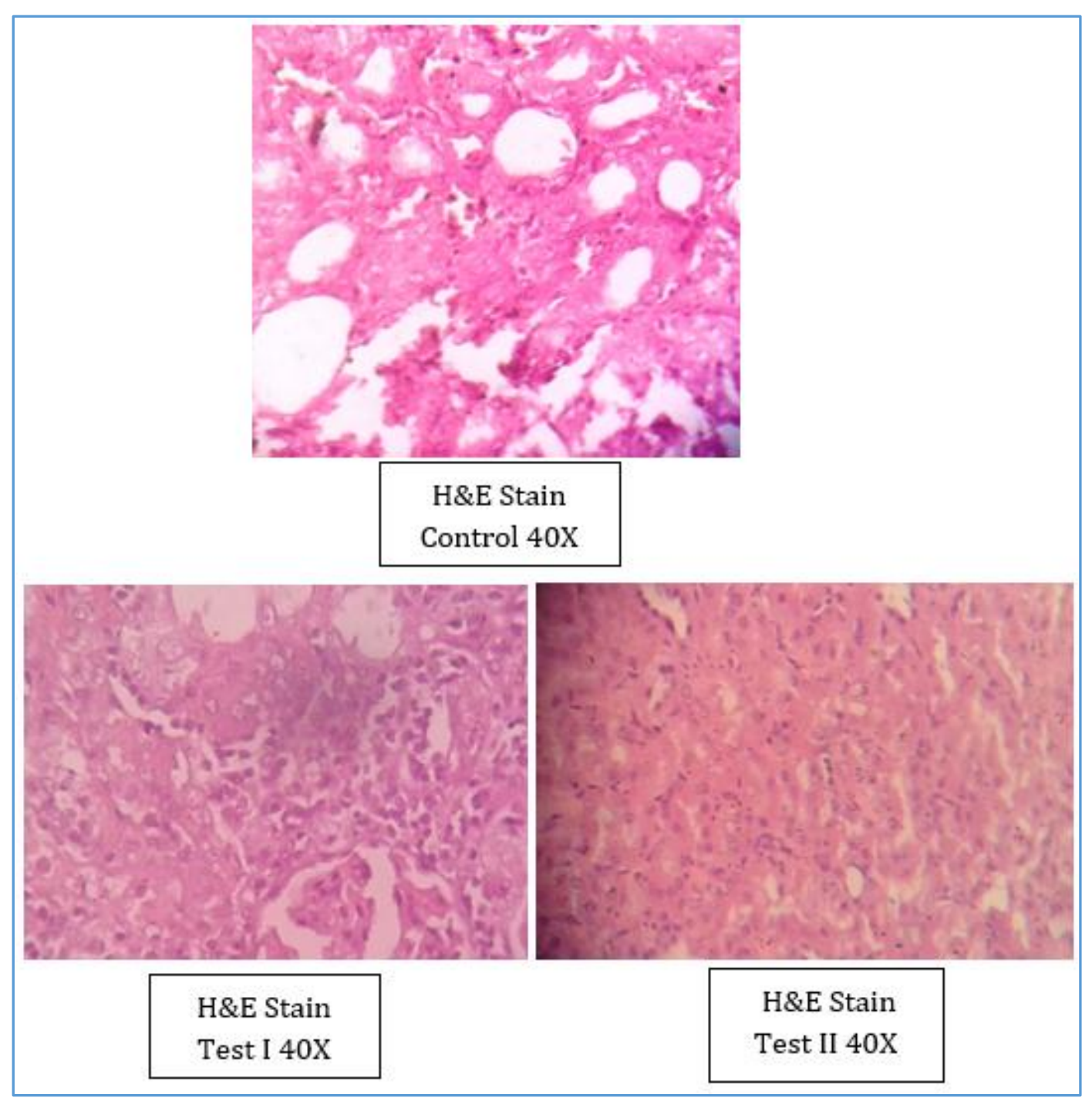

\section{DISCUSSION}

The urea and creatinine level in gentamicin induced nephrotoxicity group were significantly increased from respective baseline values to Day 5 values supporting the nephrotoxic potential of gentamicin at high dose. It strongly suggests that the mechanism may be linked to the gentamicin accumulation in renal cortex through ultrafiltration, long halflife there ( 100 hours comparing to 30 minutes in the plasma), diffusion from the tubular lumen to the apical membranes of renal proximal tubular cells by Megalin-mediated endocytosis precipitated the renal damage.[7]
The serum creatinine values after 3 weeks of treatment with NAC $20 \mathrm{mg} / \mathrm{kg}$ was $1.68 \pm 0.10$, which was significant compared to Day 5 value of $1.80 \pm 0.07$ at $P$ value $<0.05$, but the creatinine value after 3 weeks of treatment with NAC $40 \mathrm{mg} / \mathrm{kg}$ was $1.54 \pm 0.05$, which was highly significant compared to Day 5 value of $1.84 \pm 0.08$ at $P$ value $<0.001$ suggested that there was improvement in renal function by NAC in a dose dependent manner. The values on Day 26 were $1.68 \pm 0.10$ and $1.54 \pm 0.05$ respectively for test group and were found to be highly significant compared to the value for control on Day 26 at $\mathrm{P}$ 
value $<0.001$ suggesting the role of NAC in reducing the disease progression and supported the role of NAC as an antioxidant.[8]

The values of urea level on Day 26 for Test I, Test II, $47.00 \pm 1.14$ and $45.20 \pm 2.28$ were not significant compared to values on Day 5 suggesting the limitation of NAC action to halt the disease and significantly reduce the renal parameters to pre-disease condition.

The histopathological evaluation of the renal tissue at the end of Day 26 reveals severe tubular necrosis, degeneration and leucocytic infiltration in control group suggesting the nephrotoxic potential of gentamicin at high dose.[9] The tubular necrosis, degeneration and leucocytic infiltration were only moderately reduced after 3 weeks of treatment with NAC at $40 \mathrm{mg} / \mathrm{kg}$ suggesting the nephroprotective potential of NAC; however, the histological scale 4 suggests requirement of more adequate treatment of the disease condition.

\section{CONCLUSION}

The findings of the present study show that NAC produces a significant decrease in the serum creatinine values in a dose dependent manner in gentamicin induced nephrotoxicity group. In these studies, NAC at higher dose could attenuate the disease only marginally as depicted by both the renal biochemical parameters and histopathology.

\section{REFERENCES}

1. Page $\mathrm{C}$, Curtis $\mathrm{M}$, Walker $\mathrm{M}$, et al. Integrated pharmacology. Philadelphia: Elsevier 2006; $3^{\text {rd }}$ edn.
2. Katzung BG, Masters SB, Trevor AJ. Basic \& clinical pharmacology. New York: McGraw-Hill 2012;12 th edn.

3. Bello OS, Chika A. Dose dependent amelioration of Gentamicin-induced nephrotoxicity in adult swiss albino rats by Vitamin B complex. Tropical Journal of Pharmaceutical Research 2009;8(2):111-116.

4. Gowenlock AH, Mc Murray JR, Mc Lauchlan DM. Varley's practical clinical biochemistry. New York: Heinemann professional publishing Ltd Oxford 1988; $6^{\text {th }}$ edn:350-67.

5. BQRT Review of PSTC Nephrotoxicity Biomarkers. URL:http://www.fda.gov/downloads/Drugs/Developme nt Approval Process/Drug. Assessed on $10^{\text {th }}$ September 2015.

6. Indian National Science Academy. Guidelines for care and use of animals in scientific research. New Delhi: Bengal Offset Works 2000.

7. Luft FC. Gentamicin as gene therapy. Journal of Molecular Medicine 2002;80(9):543-544.

8. Bakris GL, Lass N, Gaber AO, et al. Radiocontrast mediuminduced declines in renal function: a role for oxygen free radicals. Am J Physiol 1990;258(1):115-120.

9. Yaman I, Balikci E. Protective effects of nigella sativa against gentamicin-induced nephrotoxicity in rats. Exp Toxicol Pathol 2010;62(2):183-190. 